\title{
The Value-Motivational Criterion-Based Assessment of Graduate University Teacher Education Students' Corporate Culture
}

\author{
Kira Gnyezdilova* \\ Bohdan Khmelnytsky National University at Cherkasy, Cherkasy, Ukraine \\ *Corresponding author: kiiirrra@meta.ua \\ Received September 30, 2013; Revised October 12, 2013; Accepted November 15, 2013
}

\begin{abstract}
An important component of professional culture of teachers employed within the Higher Education (HE) sector is their corporate culture. The effectiveness of corporate culture influences teaching effectiveness. Results show that there is a frequent connection between the institutional goals and corporate culture. The behavioral indicators of the faculty members and interaction with other colleagues and administration depend on the interactions of personal values with values that the university declares. Corporate culture is taught in the higher educational system. A survey conducted among prospective university teachers revealed the need to improve the teaching techniques to ensure training in corporate culture theory. The study confirmed its primary hypothesis: different universities have common features that characterize the effectiveness of corporate culture in future faculty members assessed using value-motivational criterion.
\end{abstract}

Keywords: university lecturer, faculty members' corporate culture, university corporate culture

Cite This Article: Kira Gnyezdilova, "The Value-Motivational Criterion-Based Assessment of Graduate University Teacher Education Students' Corporate Culture.” American Journal of Educational Research 1, no. 11 (2013): 512-516. doi: 10.12691/education-1-11-9.

\section{Introduction}

Current research in the field of pedagogy and psychology attaches much emphasis to the different aspects of the university lecturers' activities: their teaching-learning practices, especially the interaction between teachers and students, the effectiveness of their educational activity on the students, and their creativity in professional activities. These issues are related to the development of professional culture in the educational system as well as professional development in the sector of higher education. Some evidence exists that professional growth of faculty members and teaching effectiveness greatly depends on the university corporate culture.

On the other hand, the effectiveness of faculty members as representatives of the corporation (that is the university) depends on their ability to set appropriate behavior in the educational setting, interact with colleagues, administration within the existing rules and regulations of the university culture. It refers to the corporate culture in the prospective teacher, who has to receive the necessary training when doing the master's program.

In order to ensure the effective training of corporate culture for prospective university teachers it is necessary to identify and analyze its components. Although these results support the idea that the corporate culture helps the new employees to adjust to the university educational culture, further research could ratify these associations and probably link corporate culture with successful personal and professional growth.

\section{Subject}

Scientific interest in the corporate culture of a prospective university teacher is identified by a number of reasons. Corporate culture is not only understood as a set of values shared by people belonging with the same professional group - teaching corporation, which is also of great importance. We would also imply that corporate culture in the broadest sense combines the characteristics inherent in the national and professional (teaching) culture.

Educational setting practices indicate that faculty members - recent graduates - experience difficulties when joining a new professional community. They do not know often how to establish efficient relationships with colleagues who have quite an extensive experience and high academic status in the university. Working together as a team with other members of the educational corporations on a research project, new faculty members often have problems with making a right decision and being responsible for them. In this case new faculty members' behavioral patterns are dependent on their attitude to the faculty, the university in general, and how they accept and share the values of the university corporate culture. The study of these relationships is an important aspect of our research. 
The importance of focusing on the issue of corporate culture in prospective university teachers is a valuable trend caused by the need to change higher educational policy in the modern society. Social development requires universities to seek new directions for their activity. Due to the fact that changes are inevitable, universities may either stop functioning under the pressure of the new requirements or to work harder in order to adapt to changes and thus be able to control outcomes [1]. The institutions of higher learning are well-established and structured organizations. The change of corporate culture is a natural phenomenon because, as noted by the researchers, stability is often interpreted as a state of stagnation, not strength, and organizations that do not change are seen as hopelessly ossified [2].

Meanwhile, experience shows that the introduction of innovative techniques and methods in higher education in most cases meets the resistance or passive neglect to fulfill the tasks assigned by the administration on the part of teachers [3,4]. Such attitudes can be justified, as it is caused by teachers' conservatism, their propensity to keep the university culture intact. Traditionalism that teachers install is the key to the ability of the university to continue to maintain their traditional activities: training future professionals and developing research in different areas.

On the other hand, modern conditions under which the university functions require a revision of the business aspect of its operations. Such revision can be done through the examination of values underpinning its activities and internal integration of the most members of the teaching community. Thus, corporatism describes the highest degree of integration that characterizes the university teaching community: an association that not only shares professional values, but also nurtures human relationships within the organization, and shares the attitude to the university, its mission, goals, and objectives [5].

It is possible to ensure the support rendered by the teaching community to promote changes in the university corporate culture through their involvement in the process. The more teachers will participate in the development and introduction of corporate culture changes, the more successfully the university will develop [6].

In other words, we emphasize the need for urgent changes in corporate culture and effective university management. We believe that effective corporate culture management of the higher educational institution is possible only if we assess the value and motivational component of teachers' corporate culture.

When assessing faculty corporate culture in higher education we identified that teachers' values and those of the university where they are employed can be entirely different. Data processing has shown that university values that the university really declares do not correspond to the values and beliefs about the purposes of education that faculty members cherish. It was also found that the degree to which the university and teachers share values has a significant impact on the teachers' decision-making, conditions in educational setting for the exercise of personal initiative, and teachers' compliance with rules and regulations of organizational behavior at the institution [7].

Values underlying the university corporate culture are expressed by the behavioral regularities and group norms. In fact, the system of values is a natural regulator of teachers' behavior and serves as a tool to manage educational system and employee relationships [8,9]. The stiffness degree of the instrument used reflects the degree of the pressure on employees to observe espoused values. Permissible pressure is defined as the extension of faculty tolerance when they agree to accept values, follow behavioral patterns, rules of the games, habits and mental models [10].

Here we have a contradiction: on the one hand the teacher is a creative person who strives for creative selfrealization in professional activities; on the other hand, the rules and regulations established by the university force teachers strictly adhere to these standards and regulations without breaking the defined limits of Conduct.

The results obtained in the research made it possible to confirm the general hypothesis of the study. According to the concept, teachers' corporate culture is identified by the corporate identity, corporate behavior, and corporate relationships.

In an attempt to examine teacher's corporate culture we define corporate personal identification or belonging with an organization (university). We consider the university values and goals as such that are understood and shared by all faculty members, when teachers understand their place in the teaching community, and have an idea of an effective model of personal corporate behavior.

An important part of the corporate culture is corporate relations in higher education where teacher is engaged in the action. We need to emphasize that the engagement of all employees in order to improve the teaching effectiveness is possible if there is positive communication dynamics among faculty members and administration.

Practice shows that it has always been a significant problem for the new teacher to analyze corporate relationships in the educational setting. The new teacher finds it difficult to see human relations behind the featured role behavior, which is quite often observed in corporate relations. The contradiction between established external manifestations of role behavior and inconsistency of real human relations can sometimes be a shocking experience for new teachers. In some cases, the new faculty members after understanding the nature and complexity of real human relations in educational institutions do not maintain standards of corporate culture in their own behavior. This resistance to corporate compliance reflects disagreement of new teachers with the contradiction between the norms of corporate relations and essence of relationships among colleagues.

The research results prove that: most teachers agree that assistance rendered by the colleagues depends on the nature of the relationship among them. Successful interaction among teachers at the university depends on the extent to which the faculty members understand their own role and the role of another person in the process. You can say that role perceptions must be characteristic of these types of interactions that include: "Chair person Lecturer", "Teacher - Teacher", "Teacher - Student".

Meanwhile, a new teacher has to understand that corporate standards provide the necessary foundation for effective communication with faculty members within an educational institution that can significantly reduce the risk of conflicts in the professional community.

Corporate culture is taught to the future teachers during their master's training. The formation of each component 
of corporate culture is established by means of valuemotivational, cognitive, creative and action-reflexive criteria. So the next step in research is to assess the effectiveness of corporate culture in graduates according to the value-motivational criterion. The indicators of this criterion are: positive attitude to higher education (faculty, institute), the desire to personal identification with the university, understanding and acceptance of university values, the desire to recognize themselves as part of the teaching community in the university.

\section{Materials and Methods}

The purpose of the study was to examine the formation of a corporate culture in prospective teachers according to the value-motivational criterion. The study was conducted at seven universities in different regions of Ukraine. Participants were 283 graduate students enrolled in master's program training future university teachers.

The main hypothesis of the study was that the universities share common features that characterize the level of graduates' corporate culture according to the value-motivational criterion. Because we think that the main hypothesis is too general, we have formulated the partial hypotheses:

1) the general attitude of master students to the university is determined by perception of the department, sense of department unity, student community and faculty;

2) there are common manifestations of corporate culture by future teachers despite the differences in the university cultures;

3) formation of corporate culture in graduates according to the value-motivational criterion can be roughly divided into levels of its manifestation.

The designed questionnaire served as an instrument in the study. It included five components or indicators of corporate culture: graduates' attitude to the department (institute), attitude to the university in general, understanding the unity among the faculty (institute), graduates' perceptions of teachers as members of an educational corporation; graduates' understanding the unity of the university student body.

Respondents were asked to evaluate the proposed five statements for each of these indicators on a five point scale. For example, the indicator "My perception of the unity of the student body" has the following statements:

1) I think that students are united and support each other within the educational setting.

2) I believe that students try to support each other, but they do not communicate with each other. Students of some departments are more united than all the university taken together.

3) The students at the department associate at course and group level.

4) I think that the students only associate in the governing structures of the department and university.

5) In my opinion, students do not support each other at the university; they are hardly familiar with each other and rather passive in communication.

The important indicator to explore formation of corporate culture of future teachers is an indicator: "Faculty members as representatives of a single educational corporation". We offered the following statements to define this indicator:

1) I think that the faculty members cooperate and support each other within the university environment.

2) I believe that teachers support each other, but do not criticize each other within the university.

3) I believe that teachers cooperate more and support each other, at least, are unanimous in their requirements for student learning and performance.

4) I believe that the faculty members cooperate more within the department rather than the university.

5) I think teachers do not support each other within the university; they are hardly familiar with each other. The best argument is the different teachers' requirement for student learning and performance.

To ensure objectivity of the results evaluation it is necessary to declare that graduate students belong to a particular social group that is viewed socially active. Indeed, the graduates' attitude to the department was determined by their own efforts they invested in the activities of the corresponding department. However the contents of the activity, e.g. educational, research, sports, extracurricular, social, was not as important for the graduates as their efforts, results and social assessment of their efforts.

To process the data we calculated the sum for each indicator (Smax $=25$ ) and the total for a particular respondent $(\operatorname{Smax}=125)$.

\section{Results}

The results showed the existence of a statistically significant relationship between the graduate students attitude to the department and the university as a whole ( $\mathrm{r}$ $=0,788, \mathrm{p}<0,01$ ).

Statistically significant relationships are also established between:

1) student perceptions of teachers as representatives of educational corporations and teachers' perceptions of student unity ( $\mathrm{r}=0,694, \mathrm{p}<0,01)$;

2) graduate students' perception of the student body unity, department and university $(r=0,594, p<0,01)$;

3) graduate students' perception of the student body and their attitude to the department $(r=0,514, \mathrm{p}<0,01)$;

4) graduate students' perceptions of teachers as representatives of educational corporations and their attitude to the department and university ( $\mathrm{r}=0,504$, $\mathrm{p}<$ $0,01)$.

The study can conclude that future university teachers' attitude towards university is influenced by their attitude to the department / institute they are enrolled into.

Future teachers form their general attitude to the department on the basis of their perceptions of the student unity, department/institute and faculty members as representatives of an educational corporation. Results of the study are shown in Figure 1.

Analysis of the data revealed that despite belonging to different universities, graduate students almost equally rated each of the indicators. This conclusion was based on the comparison of frequency points prescribed by respondents to each indicator. The statistical data are shown in Table 1. 


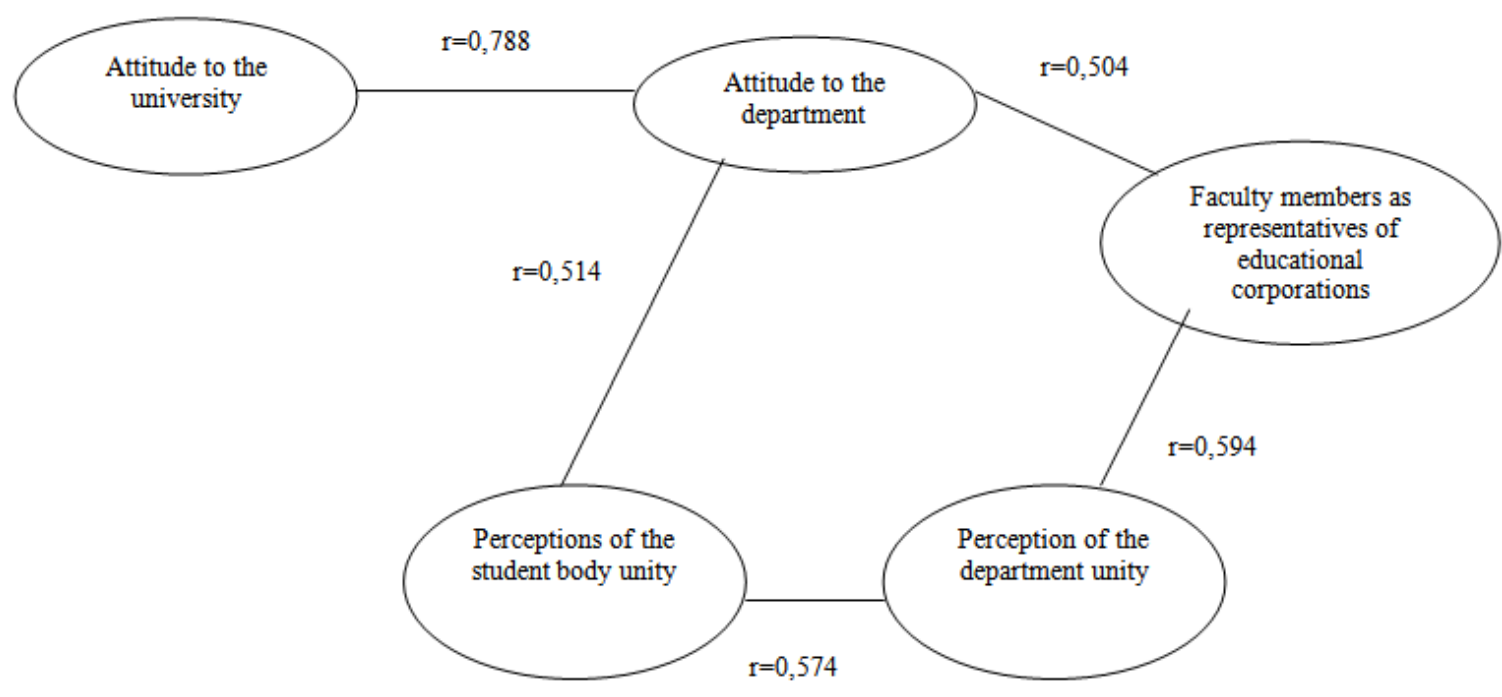

Figure 1. The relationship among indicators

Table 1. Performance and results of their evaluation

\begin{tabular}{|l|c|c|}
\hline \multicolumn{1}{|c|}{ Indicators } & Points & $\%$ \\
\hline Attitude to the department & $\begin{array}{c}18 \\
19\end{array}$ & $\begin{array}{l}10,2 \% \\
10,2 \%\end{array}$ \\
\hline Attitude to the university & 19 & $11,3 \%$ \\
\hline Perception of the department unity & 15 & $14,5 \%$ \\
\hline $\begin{array}{l}\text { Faculty members as representatives of educational } \\
\text { corporations }\end{array}$ & 18 & $15,2 \%$ \\
\hline Perceptions of the student body unity & 15 & $14,1 \%$ \\
\hline
\end{tabular}

According to the presented results it can be argued that graduate students' perception of the unity of teachers as representatives of an educational corporation plays an important role in shaping their attitude to the department. It is essential to emphasize this aspect in future university teacher training.

To assess this important indicator of corporate culture we considered all aspects of teachers' professional actions and corporate relations among them.

There were identified such important aspects as: the ability to effectively cooperate in compliance with the educational institution objectives; compliance of personal and coworkers' professional requirements with the corporate standards; objective assessment of colleagues' professional skills and their work, the ability of teachers to support the colleagues' reputation and not to destroy it; teachers' unity and mutual support in interaction with students, the ability to feel and share co-workers' the feelings and emotions.

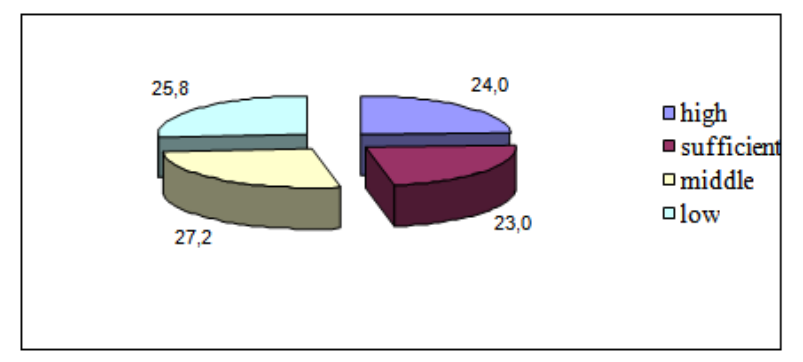

Figure 2. Corporate culture effectiveness assessed with the valuemotivational criterion

According to the information received we attempted to evaluate the efficiency of corporate culture in graduate students according to the value- motivational criterion. We also described this criterion in levels according respondents' responses. The diagram is shown in Figure 2.

Analysis of the results presented makes us consider the fact that $27.2 \%$ of respondents showed a low level of corporate culture according to the value-motivational criterion. This means that $25 \%$ of teachers did not share the university values nor they adhere to them while pursuing personal careers; they do not appreciate the educational institution where they work.

In this case, the efforts of this group of teachers do not coincide with the efforts of the majority of teachers of educational institutions; they do not promote their actions and the university activities, its goals and objectives. This group of teachers can be called "destructive" to the university corporate culture and its values.

The group of teachers rated with the middle level makes 25.8\%; these teachers do not share the university values either. They put up with the values suffering in the process and do not consider them meaningful.

Thus, the study proved that almost half of the faculty members are unable to actively support the corporate culture values in the higher educational setting.

The results demand more attentive attitude to corporate culture teaching to future university teachers during their master's program training. The earlier the future teachers comprehend and understood the importance of corporate rules, the more positive they will perceive university values, goals and objectives, the more effort they will put in the pursuing in their own careers.

We offer to include the graduate course "Corporate Culture of a University Teacher" to improve training of future teachers. It will familiarize graduates with the idea of a university professional corporate culture, its components and indicators, its impact on the university effectiveness as well as the relationship between corporate culture of educational institutions and teacher's corporate culture.

An important component is the procedural part of the proposed course. It should combine group work (teamwork) and individual work. The use of such techniques as a project study, workshops, games, methods of collective decision-making will improve the corporate culture of the future high school teachers. The creation of 
such programs and courses helps revise and transform the future teachers' values. During these sessions it is important to exchange social roles of future teachers.

\section{Conclusion}

During the training of future university teachers provided by higher educational system, an important issue is to develop a corporate culture in the course of master's program training. The quality of its formation is determined by the value-motivational criterion that shows how values, goals and objectives of the university are understood and shared by future university teachers. The results of the study confirmed the hypothesis that there exists interdependent relationship between university corporate culture and university teacher's corporate culture at the level of the value-motivational criterion.

\section{References}

[1] Clark, Burton R., Sustaining Change in Universities. Continuities in Case Studies and Concepts, The Society for Research into
Higher Education \&Open University Press / SL6 2QL, England: McGraw-Hill, 2004.

[2] Cameron, Kim S., Quinn Robert E., Diagnosing and changing organizational culture: based on the competing values framework, Jossey-Bass San Francisco, 2006, 242.

[3] Beliaev, A., "University Corporate Culture: from Theory to Practice”, Higher Education in Russia, № 11, 62-65, 2007.

[4] Andomin, O. V., Kosinova, S. N., "University Corporate Culture as Pedagogical Problem”, Book of Publications at SamSU, № 5/2 (64), 201-209, 2008.

[5] Korotkov, E. M., Management of Quality Education, Academic Project: Peace, Moscow, 2006, 277.

[6] Poholkov, Yu. P., Pushnyh, V. A., Mitrofanova, M. V., "Corporate Culture at Russian Technical Universities”, Book of University Publications, № 9, 66-71, 2011.

[7] Gnyezdilova, K. N., "Study on Correlation Relationships between Components of University Lecturer's Organizational Culture”, Scientific Dialogue. Pedagogy, № 8 (20), 52-64, 2013.

[8] Khoruzhy, H. F., Academic Culture: Values and Principles in Higher Education, Navchal'na knyha - Bohdan, Ternopil, 2012, 320.

[9] Andrushchenko, V., "Education: Tendencies in Changes", Higher Education in Ukraine, № 2. 5-15, 2012.

[10] Andrieeva, I. V., Betina, O. B., Kosheleva, S. V., "Sociocultural Approach to Assess Corporate Values", Book of Publications SPbG, Ser. 8, Vol. 1. 77-95, 2008. 